\title{
RADIOFREQUENCY ABLATION OF OSTEOID OSTEOMA IN CHILDREN, SHORT TERM RESULTS
}

\author{
Costel Vlad ${ }^{1}$, Laura Popa ${ }^{1}$, Camelia Vreme ${ }^{2}$, Ștefana Carp ${ }^{1}$, Eduard Liciu ${ }^{1}$, Diana Ionescu ${ }^{1}$
}

\section{Abstract}

The purpose of this paper is to evaluate the postoperative results in paediatric patients with osteoid osteoma. We present a retrospective study including 16 patients under 18 years old treated surgically in our institution between April 2019 and September 2020. Patient demographic data, clinical aspects and imaging studies used to establish the diagnosis, lesion location, the size of the nidus, surgical data, hospitalization periods, complications and particular conditions were noted.

Sixteen patients with mean age of 11.19 years (between 5 and 17 years) were treated using surgical excision (open or minimal invasive) or radiofrequency ablation (RFA). All patients presented with night pain highly responsive to nonsteroidal anti-inflammatory drugs. Imaging studies before surgery included radiographs, CT scans and/or MRI, technetium-99 bone scans. Interval between symptoms onset and surgery varied from 3 to 18 months (mean 8.18 months). Eight patients were treated using radiofrequency ablation under fluoroscopy, 5 cases were treated using minimal invasive surgery (resection-biopsy with trocar) and 3 cases were treated by open surgical excision. We have obtained histopathologic diagnosis in all cases. One patient had a superficial wound infection and two patients presented recurrent pain. In 13 patients the pain disappeared during the first 48 hours after surgery. Mean follow-up time was 10.12 months.

RFA is the treatment of choice in paediatric cases of osteoid osteoma. Vicinity of important anatomical structure are contraindications for RFA. Using ablation probes with cooled tips may result in more predictable outcomes. The tendency to use less and less invasive procedures in the surgical fields seems to lead to development of non-invasive procedure.

Keywords: osteoid osteoma, children, radiofrequency ablation, cooled tip

\section{Introduction}

Osteoid osteomas are benign, painful, solitary lesions of bone. Described by Jaffe in 1953 [1] is still subject of research for new treatments. Osteoid osteoma consists of a central round nidus of $1.5-2 \mathrm{~cm}$ surrounded by an area of dense reactive bone. The central nidus is composed by variable amounts of osteoid, osteoblasts and fibrovascular stroma. The cortical bone adjacent to osteoid osteoma may be pink due to increased local vascularity. The lesion is a round or oval reddish tumour less than $2 \mathrm{~cm}$, most frequently around $1 \mathrm{~cm}$. The nidus may be very dense if the calcification process is intense or may be soft or granular if calcification is little. Osteoid osteoma presents small spicules of immature trabeculae lined by osteoblast and osteoclasts. The pain associated to osteoid osteoma is generated by nonmyelinated axons present in the nidus.

The typical presentation is of localized, nocturnal, or quasi continuous pain, related to the nidus location, alleviated by salicylates or other NSAIDs intake. The pain may be cause of misdiagnosis, for example a femoral neck osteoid osteoma may generate pain to the knee and viceversa, imagistic exam being misoriented by consequence. According to the affected limb, a limp may be present or another functional impairment. Muscular atrophy is always present in variable extent. Local swelling is uncommon. In cases of vertebral osteoid osteoma, a muscle contracture may develop. On conventional X-ray the nidus may be visible, on occasion central calcification may be present. In unusual locations, when reactive sclerosis is not visible bone scintigraphy may be necessary to reveal the location. CT scan and MRI are useful tools for diagnosing this entity.

The treatment of osteoid osteoma evolved over time. There is always place for conservative treatment due to fear of surgery or difficult approach [2, 3]. Surgical treatment and open or percutaneous resection of the lesion are available options [4]. Modern techniques, such radiofrequency ablation, are widely used today to treat osteoid osteoma [5, 6]. Other emerging techniques are developing such cryoablation [7] or magnetic resonance focused ultrasound [8].

The purpose of this paper is to present the short-term results obtained in our department with the treatment of osteoid osteoma in children and to report the early results with radiofrequency ablation (RFA) in children with osteoid osteoma.

\section{Materials and Methods}

From April 2019 to September 2020 sixteen patients with osteoid osteomas were treated by our team (Table 1).

${ }^{1}$ Clinical Hospital for Children "Dr Victor Gomoiu”, Department of Paediatric Orthopaedics, Bucharest, Romania 'Emergency Hospital for Children "Maria Sklodowska Curie”, Department of Paediatric Orthopaedics, Bucharest, Romania E-mail: costelvlad.cv@gmail.com,1.lauradobre@gmail.com, camelia1990_camelia1990@yahoo.com, stefana.carp@gmail.com, liciueduard@gmail.com,diaionescu@gmail.com

Table 1: The case series of 16 patients with osteoid osteoma operated in our department. 


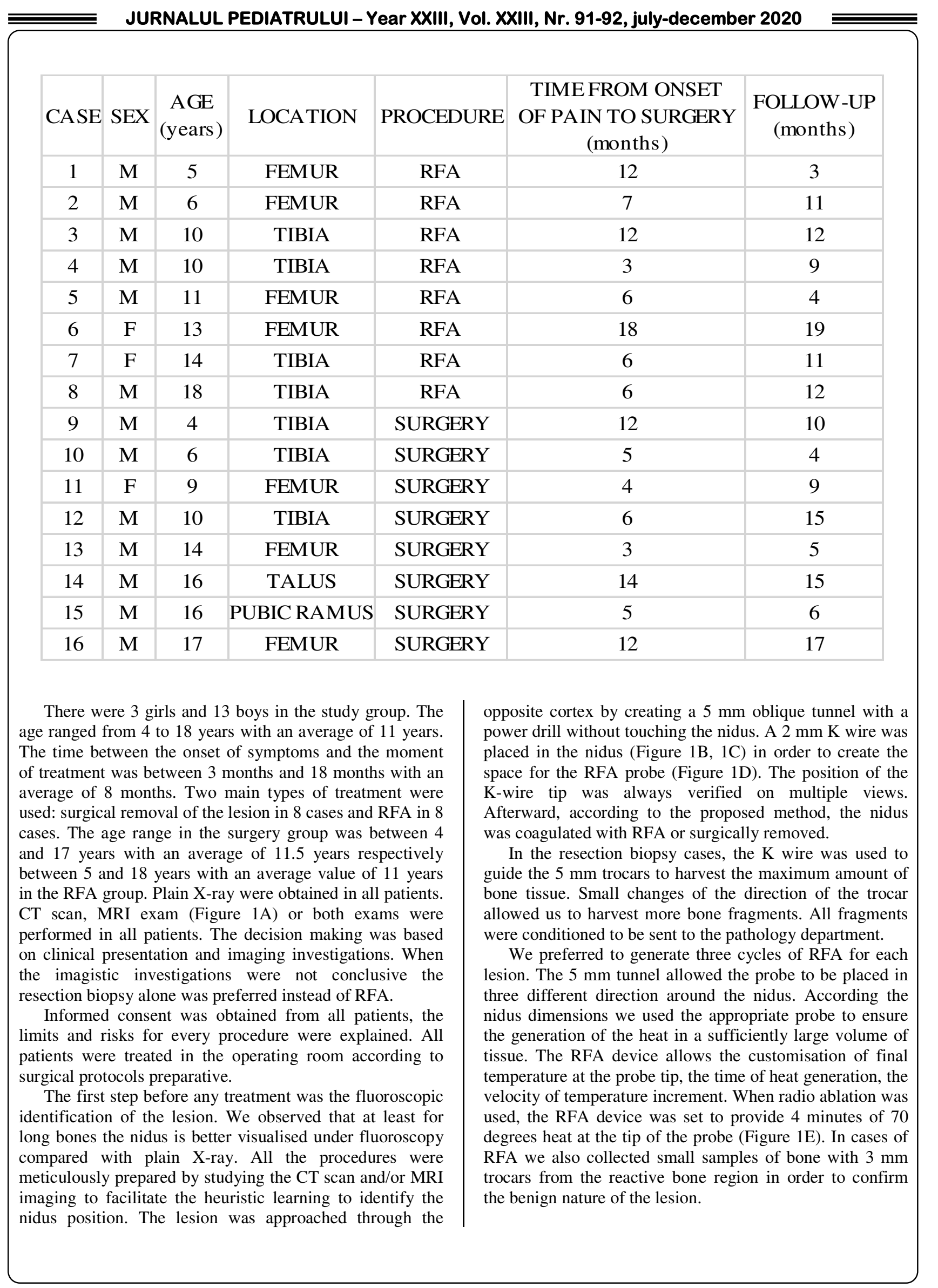




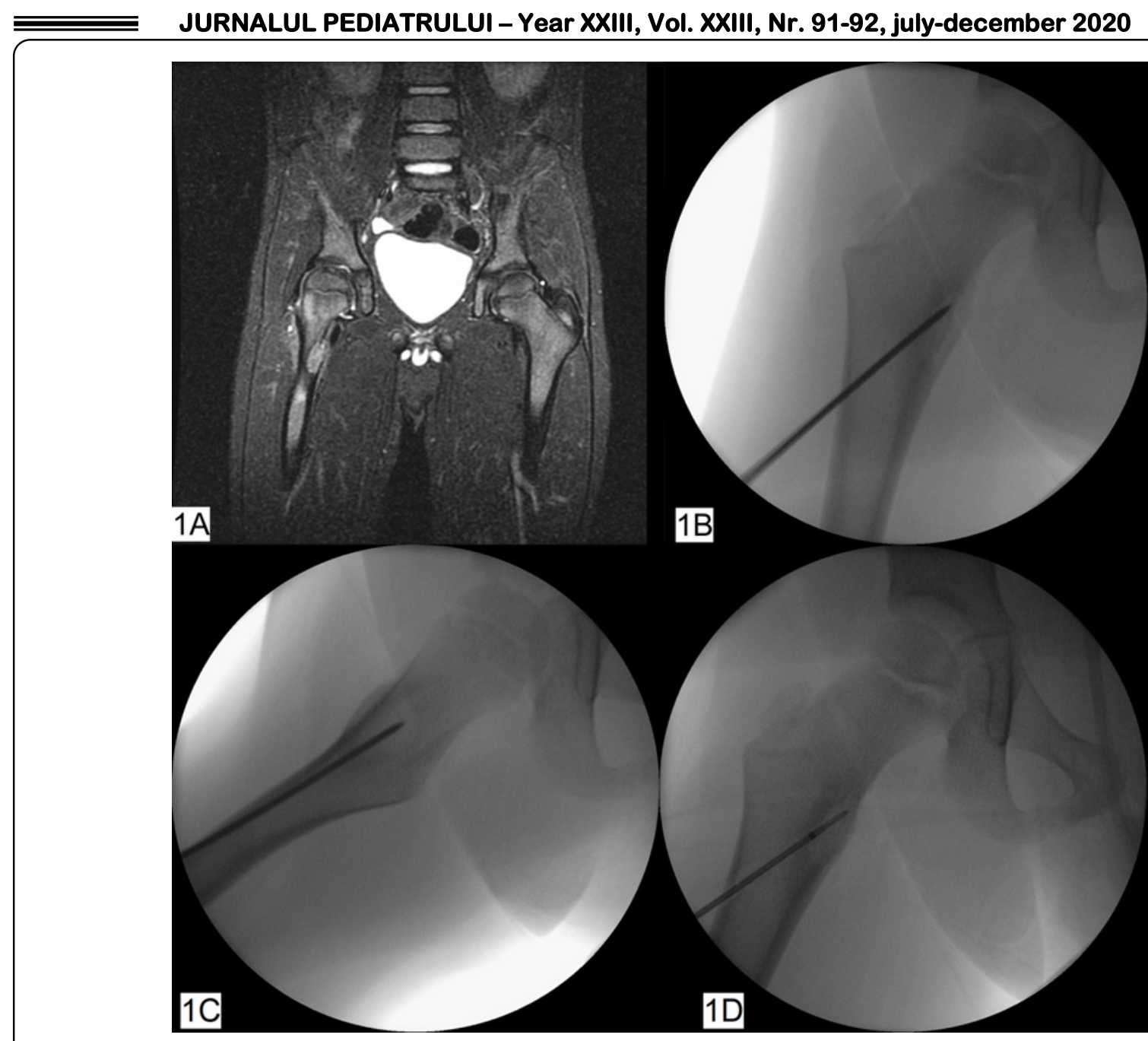

Figure 1. A - Case no.1, MRI aspect of the right sub trochanteric osteoid osteoma. B - K wire placement under fluoroscopic control, anteroposterior view. C - K wire placement under fluoroscopic control, lateral view. D - The fluoroscopic image of RFA probe in the nidus.

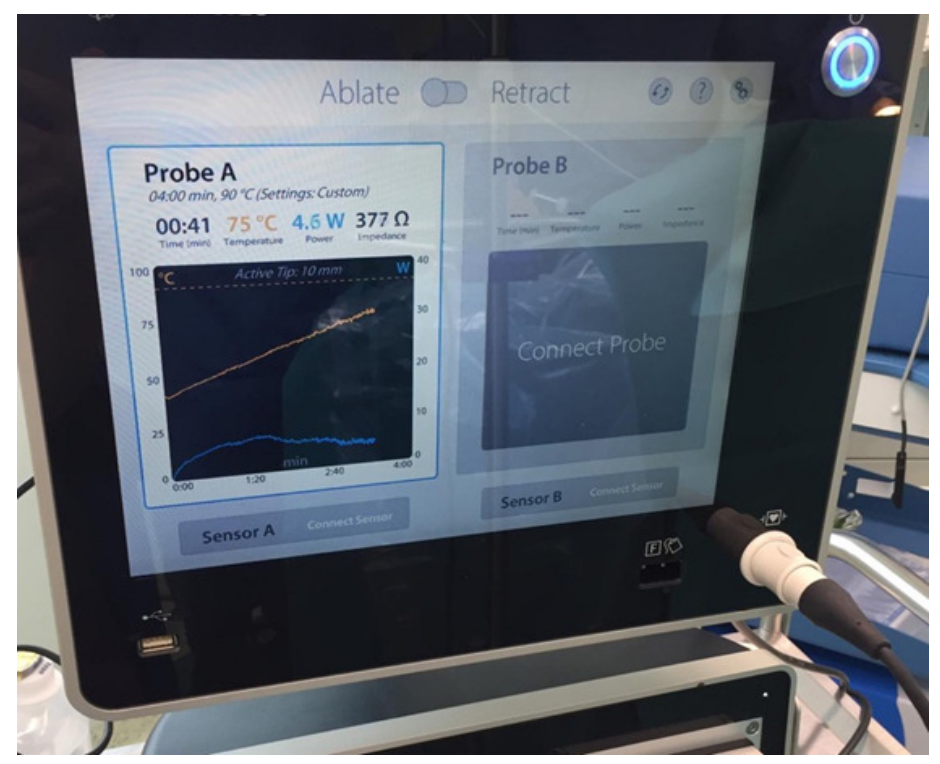

Figure 1E. The RFA device showing the temperature curve control (yellow line). 


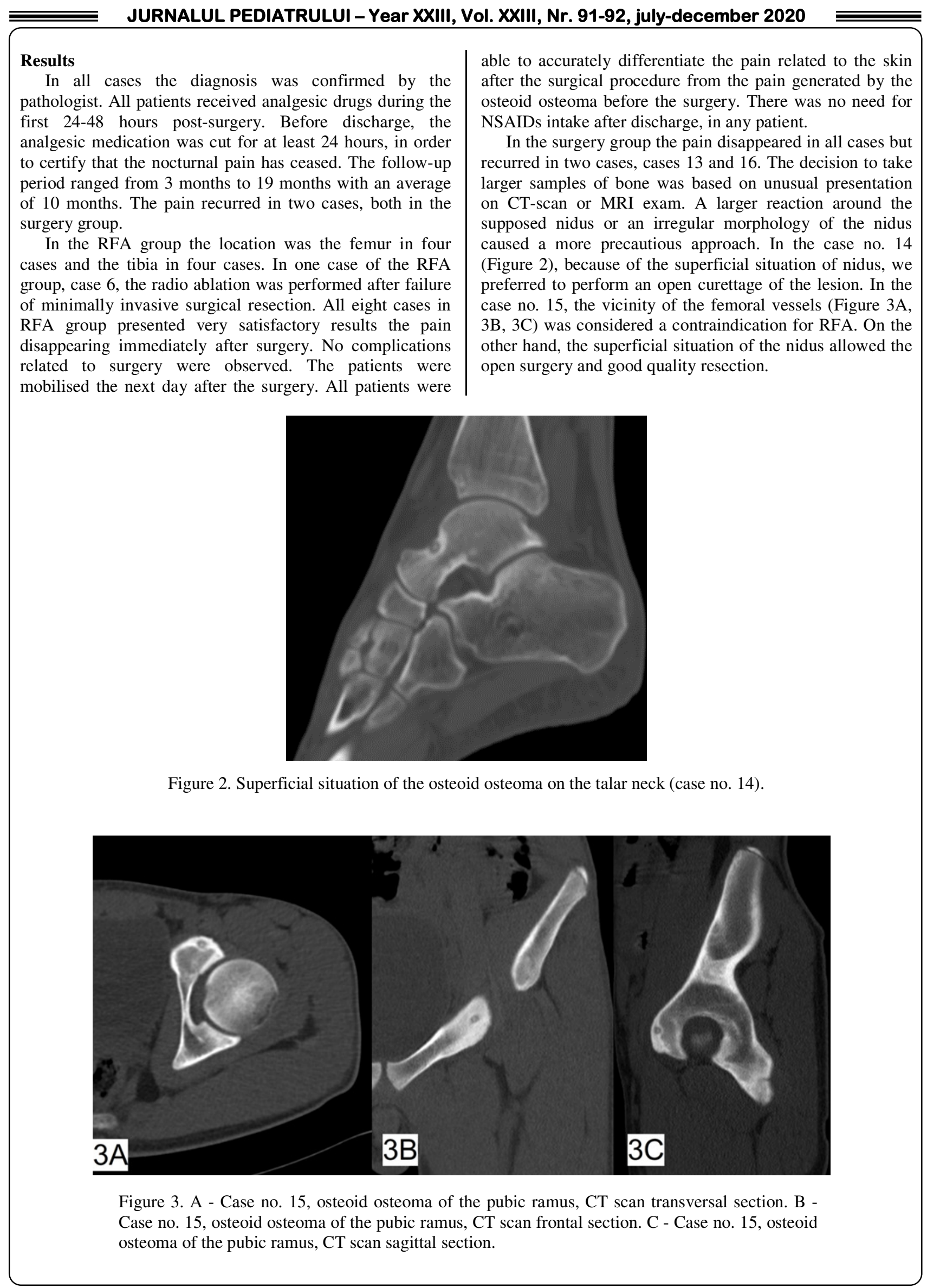




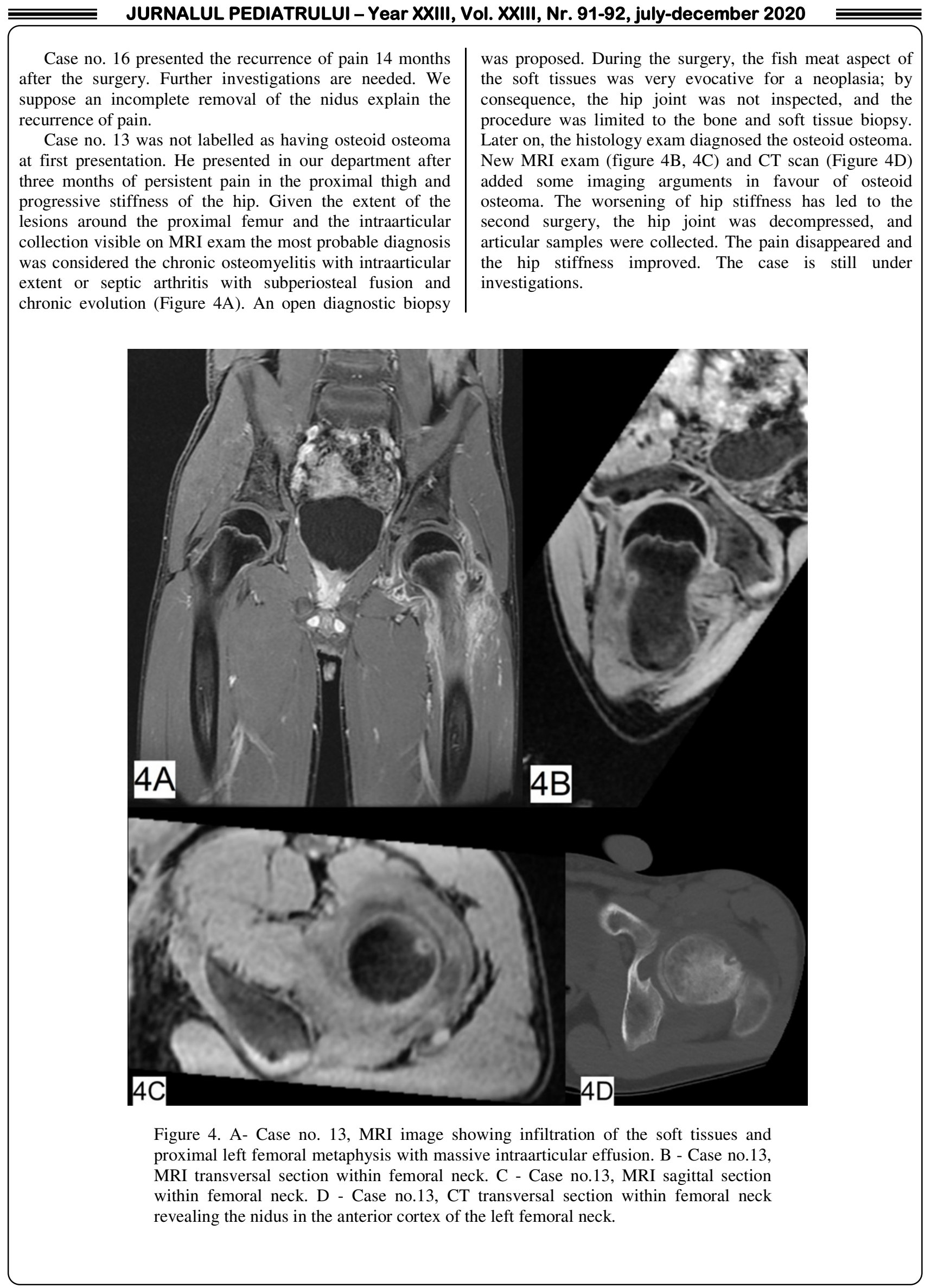




\section{Discussion}

Rosenthal [9] is credited to be the first to use the radiofrequency to ablate the osteoid osteoma. The principle of the method consists of creating a heating process in a controlled volume of tissue in order to destroy the proteins in the tissue. The denaturation of the proteins will have two consequences: the bone forming process will stop and the nervous fibbers in the tumour tissues will be destroyed so the pain stimuli will not pass. The problem of the heating process control was addressed by new technical development. The water-cooled probes used for RFA seems to produce more predictable and lasting effects on tissue denaturation [10]. Zacharias et al., in an experiment on mice, proved that the amount of energy generated in tissue is higher for the cooled-tip probe [10]. Another physical process to consider is the velocity of temperature increase. A too rapid increase in the temperature will necrotise the protein rapidly, on a small radius around the probe; a slow increase of the temperature will allow a more uniform denaturation of the protein on larger radius.

In a study on 263 patients the efficacy of RFA was evaluated to $91 \%$ for procedures performed as initial treatment and $60 \%$ for recurrent lesions by Rosenthal et al [11]. Long term results were not influencing by age, sex, location of the lesion. Few authors evaluated the success rate of RFA in children with comparable results [12-14]. The safety of the procedure was proved by the low rate of complications. When comparing to the resection-biopsies there are few advantages to emphasise. Removing a bone fragment may alter the mechanical strength of bone becoming susceptible to fracture. RFA does not alter the mechanical strength of the affected bone. The recurrence of the symptoms is caused by the incomplete removal of the lesion. The advantage of RFA consist in the possibility of treating a larger volume of tissue without removing it, we performed a few cycles of radio ablation around the nidus to prevent recurrence.

Our case series is not statistically significant to emit some conclusions concerning the efficacy of the RFA in the treatment of osteoid osteoma in children, but it allowed us to learn some lessons. First of all, the use of RFA is reassuring for the surgeon. There is no fear about the consequences of missing the lesion as in open surgery when visual identification of the nidus is almost impossible. Even in case of failure to identify and coagulate the nidus there is always the possibility to return to operating room without the consequences of an excisional procedure. Another lesson consists in heuristic learning to identify the bone anatomy.
Some papers report the results with 3D navigation to identify the nidus which is safer [15]; a thoroughly study of 3D reconstruction on CT or multiplanar reconstructions on MRI will train the surgeon to have good mono-planar landmarks on fluoroscopy in the operating room. An empirical observation consists of that the nidus is easier to identify on fluoroscopic images than on plain X-ray.

All cases in our series which raised concerns about the positive diagnosis of osteoid osteoma were confirmed at histologic exam. The cautions may never be enough, but the probable diagnosis based on non-invasive imagistic technique is a grey-zone subject to local regulations among experts, in order to avoid unexpected misdiagnosis. In case of doubt, having a histologic confirmation, is advisable.

Intraarticular or juxtaarticular location of the osteoid osteoma is a subject of concern given the extent of local reaction of soft tissues. Intraarticular locations of osteoid osteoma are less common, representing $12 \%$ of all lesions, and the hip is the most frequently affected joint [16-18]. Intraarticular osteoid osteoma may produce a wide spectrum of manifestations as soft tissue swelling, joint tenderness, effusion, and synovitis, simulating inflammatory arthritis or degenerative arthropathy [19-21]. Growth disturbances or scoliotic deformity were reported in skeletally immature patients, and intraarticular lesions can create a chronic inflammatory cascade leading to osteoarthrosis [22, 23]. Alternative initial diagnosis and delays in diagnosis are common due to the rarity of the location about the hip of the osteoid osteoma and to the unclear clinical and imaging findings [24]. Erroneous diagnosis was found in 22 of 31 patients by Goldberg and Jacobs, with synovitis and LeggCalvé-Perthes disease being most common [25]. Delays in diagnosis can lead to prolongation of symptoms and can produce skeletal deformity, scoliosis, and if located intraarticular, joint degeneration [22, 23, 26, 27].

\section{Conclusions}

RFA is the treatment of choice in paediatric cases of osteoid osteoma. Vicinity of important anatomical structure are contraindications for RFA. Using probes with cooled tips may result in more predictable outcomes. The tendency to use less and less invasive procedures in the surgical fields seems to lead to development of non-invasive procedure.

\section{Conflicts of interest}

The authors declare that they have no conflict of interests.

\section{References}

1. Jaffe HL. Osteoid-osteoma. Proc R Soc Med. 1953;46(12):1007-12. Epub 1953/12/01. PubMed PMID: 13120827; PMCID: PMC1918782.

2. Yokouchi M, Nagano S, Shimada H, Nakamura S, Setoguchi T, Kawamura I, Ishidou Y, Komiya S. Early complete remission of osteoid osteoma with conservative medical management. Pediatr Rep. 2014;6(1):5311. Epub 2014/04/09. doi: 10.4081/pr.2014.5311. PubMed PMID: 24711915; PMCID: PMC3977163.

3. Jayakumar P, Harish S, Nnadi C, Noordeen H, Saifuddin A. Symptomatic resolution of spinal osteoid osteoma with conservative management: imaging correlation. Skeletal Radiol. 2007;36 Suppl 1:S72-6. Epub 2006/09/13. doi: 10.1007/s00256-006-0198-x. PubMed PMID: 16967288. 
4. Baunin C, Puget C, Assoun J, Railhac JJ, Cahuzac JP, Clement JL, Sales de Gauzy J. Percutaneous resection of osteoid osteoma under CT guidance in eight children. Pediatr Radiol. 1994;24(3):185-8. Epub 1994/01/01. doi: 10.1007/bf02012187. PubMed PMID: 7936795.

5. Ghanem I, Collet LM, Kharrat K, Samaha E, Deramon H, Mertl P, Dagher F. Percutaneous radiofrequency coagulation of osteoid osteoma in children and adolescents. J Pediatr Orthop B. 2003;12(4):244-52. Epub 2003/06/25. doi: 10.1097/01.bpb.0000049571.52224.81. PubMed PMID: 12821840.

6. Göksel F, Aycan A, Ermutlu C, Gölge UH, Sarısözen B. COMPARISON OF RADIOFREQUENCY ABLATION AND CURETTAGE IN OSTEOID OSTEOMA IN CHILDREN. Acta Ortop Bras. 2019;27(2):100-3. Epub 2019/04/17. doi: 10.1590/1413-785220192702158113. PubMed PMID: 30988655; PMCID: PMC6442716.

7. Wu B, Xiao YY, Zhang X, Zhao L, Carrino JA. CTguided percutaneous cryoablation of osteoid osteoma in children: an initial study. Skeletal Radiol. 2011;40(10):1303-10. Epub 2011/02/12. doi: 10.1007/s00256-011-1119-1. PubMed PMID: 21311882.

8. Arrigoni F, Napoli A, Bazzocchi A, Zugaro L, Scipione R, Bruno F, Palumbo P, Anzidei M, Mercatelli D, Gravina GL, Zoccali C, Ghanouni P, Barile A, Catalano C, Masciocchi C. Magnetic-resonance-guided focused ultrasound treatment of non-spinal osteoid osteoma in children: multicentre experience. Pediatr Radiol. 2019;49(9):1209-16. Epub 2019/05/28. doi: 10.1007/s00247-019-04426-0. PubMed PMID: 31129699.

9. Rosenthal DI, Alexander A, Rosenberg AE, Springfield D. Ablation of osteoid osteomas with a percutaneously placed electrode: a new procedure. Radiology. 1992;183(1):29-33. Epub 1992/04/01. doi: 10.1148/radiology.183.1.1549690. PubMed PMID: 1549690.

10. Zachariah C, Mayeux J, Alas G, Adesina S, Mistretta OC, Ward PJ, Chen A, English AW, Washington AV. Physiological and functional responses of water-cooled versus traditional radiofrequency ablation of peripheral nerves in rats. Reg Anesth Pain Med. 2020;45(10):7928. Epub 2020/08/14. doi: 10.1136/rapm-2020-101361. PubMed PMID: 32784232; PMCID: PMC7513268.

11. Rosenthal DI, Hornicek FJ, Torriani M, Gebhardt MC, Mankin HJ. Osteoid osteoma: percutaneous treatment with radiofrequency energy. Radiology. 2003;229(1):171-5. Epub 2003/08/29. doi: 10.1148/radiol.2291021053. PubMed PMID: 12944597.
12. Albisinni U, Chiatante M, Rinaldi R. Efficacy of percutaneous radiofrequency ablation of osteoid osteoma in children. Pediatr Radiol. 2008;38(12):1356. Epub 2008/09/18. doi: 10.1007/s00247-008-0986-7. PubMed PMID: 18797860.

13. Donkol RH, Al-Nammi A, Moghazi K. Efficacy of percutaneous radiofrequency ablation of osteoid osteoma in children. Pediatr Radiol. 2008;38(2):180-5. Epub 2007/11/28. doi: 10.1007/s00247-007-0690-z. PubMed PMID: 18040677.

14. Hage AN, Chick JFB, Gemmete JJ, Grove JJ, Srinivasa RN. Percutaneous Radiofrequency Ablation for the Treatment of Osteoid Osteoma in Children and Adults: A Comparative Analysis in 92 Patients. Cardiovasc Intervent Radiol. 2018;41(9):1384-90. Epub 2018/04/14. doi: 10.1007/s00270-018-1947-7. PubMed PMID: 29651579.

15. Rajasekaran S, Karthik K, Chandra VR, Rajkumar N, Dheenadhayalan J. Role of intraoperative 3D C-armbased navigation in percutaneous excision of osteoid osteoma of long bones in children. J Pediatr Orthop B. 2010;19(2):195-200. Epub 2009/12/03. doi: 10.1097/BPB.0b013e328333997a. PubMed PMID: 19952798.

16. Gaeta M, Minutoli F, Pandolfo I, Vinci S, D'Andrea L, Blandino A. Magnetic resonance imaging findings of osteoid osteoma of the proximal femur. Eur Radiol. 2004;14(9):1582-9. Epub 2004/03/12. doi: 10.1007/s00330-004-2293-5. PubMed PMID: 15014975.

17. Freiberger RH, Loitman BS, Helpern M, Thompson TC. Osteoid osteoma; a report on 80 cases. Am J Roentgenol Radium Ther Nucl Med. 1959;82(2):194205. Epub 1959/08/01. PubMed PMID: 13670322.

18. Cohen MD, Harrington TM, Ginsburg WW. Osteoid osteoma: 95 cases and a review of the literature. Semin Arthritis Rheum. 1983;12(3):265-81. Epub 1983/02/01. doi: 10.1016/0049-0172(83)90010-0. PubMed PMID: 6603021.

19. Franceschi F, Marinozzi A, Papalia R, Longo UG, Gualdi G, Denaro E. Intra- and juxta-articular osteoid osteoma: a diagnostic challenge : misdiagnosis and successful treatment: a report of four cases. Arch Orthop Trauma Surg. 2006;126(10):660-7. Epub 2006/08/24. doi: 10.1007/s00402-006-0203-9. PubMed PMID: 16927097.

20. Corbett JM, Wilde AH, McCormack LJ, Evarts CM. Intra-articular osteoid osteoma; a diagnostic problem. Clin Orthop Relat Res. 1974(98):225-30. Epub 1974/01/01. doi: 10.1097/00003086-197401000-00026. PubMed PMID: 4817234. 
